lege, like Keble College, seems to answer it in another. The present extravagant cost of residence at Oxford and Cambridge, which elicits the groans of many a paterfamilias, is shown not to be a necessity; if it were unavoidable, it would be an argument against the admission of the bulk of medical students to the universities which would silence me. There are many who value their university residence rather because it is a proof of their parents having been wealthy, than because they have any superior acquirements to boast of ; but I do not think so meanly of the ruling powers as to believe that they would desire to make property the qualification of primary consideration in the test of admission. The heartiness with which the universities have, during the last twenty years, thrown themselves into the great question of educational reform, and given material aid to its intrinsic development, is the best proof that they recognise their high mission. At the same time, it may be doubted whether their energies in directing middle-class examination are not somewhat misplaced. We all know one or more benevolent ladies, whose labours for the clothing-clubs, soup-kitchens, visiting and missionary societies of their parish, are unlimited, but whose children are allowed to run wild from want of that home-supervision which their mother's expansive benevolence prevents her from exercising.

Does not Alma Mater also tend, with due reverence be it said, to a partial neglect of those duties which lie nearer home, in order that she may acquire the name of an universal foster-mother? At all events, if she has spare energies for the chickens that are wandering about untended and uncared for, she ought surely first to show that her own brood has received the necessary food and protection, and that she has guarded them from becoming the prey of the designing and watchful fox.

Whether our Association can take active steps towards. the consummation of what I would fain hope many of my hearers may consider to be a desirable object, is a question that I dare not now dwell upon at large; but I entreat your permission to add a few more words on the subject. I apprehend we have in the first instance to consider, not so much whether it is possible for Oxford or Cambridge to receive our students, as to determine whether it is right and proper that the future generation of medical men shall receive their scientific training at an university or not. If the affirmative be adopted, we may then make our wishes respectfully known to the authorities of the old universities If they read the signs of the times with our interpretation, we should do well to benefit by the prestige of their ancient names, and it would be a matter of rejoicing that those seats of learning would secure the advantages which it is believel would accrue to them. The alternative of a new foundation in a southern or northern county town would still remain. For my own part, I venture to think that, if you endorse the views I have offered to you, we should more speedily gain our ends if this great Association resolved that a new university, in which the professorial element shall be paramount, is necessary; and proceeded to take such steps as prudent foresight may suggest to secure the realisation of so great an end.

If I have succeeded in obtaining your sympathies, I have little doubt that the ways and means will be forthcoming to enable us to meet what I regard as the summons of the spirit of progress and science, aldressed to ourselves and our contemporaries. If you differ from me, I crave your pardon for having taken up your time unnecessarily; but I should scarcely have been true to myself if I had not seized an opportunity, such as the indulgent offer of your Council has given me to-day, of placing before you a summary of the great work that our Association has done, and the still higher objects that I believe it to be destined to achieve. Salvavi animam miam.

When I was first invited to deliver this address, I was told that I should meet you at one of the most frequented health-resorts of England, and I naturally asked myself whether I might not appropriately select some topic of general medical interest connected with hygiene, climatology, or balneology, to enlarge upon; but, on review of the past history of our Association and of its influence on our common profession, I could not resist the temptation to take a larger scope, and to ask you whether we are to rest satisfied with what our predecessors have done for us, or whether we should not rather emulate their great endeavours, and seek to place medicine on a higher social, political, and scientific platform. Sloth and stagnation are not to be thought of here, in the very centre of England's manufacturing greatness. Everything that surrounds challenges us with the watchword, " Excelsior !" Morlern life is a continuous and hard-fought battle of the intellect. Muscular Christianity is necessary to sustain and invigorate the body; but the training requisite to sustain the mind at its highest point of development is surely now more than ever a question of national importance. The workers in brass and iron, no less than the practitioners of medicine, are indebted to science for their greatest achievements.
What say you? Is it possible for the British Medical Association to do more than has yet been done to place science on a footing worthy of an empire upon which the sun never sets? Can this very meeting take steps to inaugurate a new university in which none shall enter but those who, being well prepared for its curriculum, shall be capable of receiving a training by the highest intellects of the country for even higher work in ail that adorns and elevates life?

I cannot hope to carry all your suffrages with me ; but, however our views may differ, I am satisfied that we all agree in our reverence for the great names of the past, and in our desire to tread in the footsteps of those who have led us to the position we now occupy.

That we may more and more be enabled to work with and for the growth, physical and intellectual, of our fellowmen, that we and our children's children may become more and more identified with our country's greatness, has been the wish that has prompted the thoughts which thus imperfectly and fragmentarily I have ventured to lay before you, the Members of the British Medical Association.

\section{ADDRESS IN SUR'GERY,}

\author{
W. F. F A V E L L, M.R.C.S.ENG., \\ Surgeon to the Infirmary, Sheffield.
}

Mr. President and Gentlemen,-In the first place, allow me to thank the members of the British Medical Association, and particularly those members who are my fellow-townsmen, for the high honour they have conferred upon me in putting this address into my hands; at the same time, when I consider how many amongst the wisest and most eminent of British surgeons have delivered this address in Surgery before me, I feel how little anything I can say can rival the memorable utterances of by-gone years, and how much I need (what I know I shall get), viz., the indulgent hearing of the distinguished company here to-day.

If I can tell you nothing new to attract your attention or excite your admiration, I hope I may be able to say something useful, and, at all events, to draw attention to facts which will bear investigation again and again. Bearing in mind the rapid advances made in surgery within the last few years, and bearing in mind also the constant changes in surgical practice, it has appeared to me that it is well sometimes, on an occasion like the present, to pass in review some few of the most important changes in practice, comparing them, as far as we can, with recorded results of past experience.

Alterations are by no means necessarily improvements; and, in this age of rapid progress, are we not sometimes in danger of setting too light a value on the things of the past, and of too utterly discarding some remedial measures to which our predecessors attached immen e importance? Permit me, in illustration, to quate the words of one of the wisest and most eloquent of surgeons, Sir James Paget. In a very charming and graceful paper, read at the opening of the Section of Surgery at Norwich two years ago, Sir James, referring to his notebook of cases recorded forty years previously, says: "I found there some things which make me still fear, lest in our progress we should have let fall some things which we had better have held, and are now regarding some things too lightly that then seemed very grave, and, perhaps, are so still. For, among the records which I found, are records of methods of practice now almost completely disused, and yet in which I feel confident there was much right. I find, for example, a large and almost uniform practice of bleeding for all acute diseases, for many chronic, for most of those which were unknown and uncertain, and for a large proportion of those in which there seemed to be nothing the matter. Trying to learn something from these things, I come to one or two conclusions, which I am sure the younger members of the profession need to have much impressed upon them. One of them is, that at the present day we undoubtedly overvalue the blood, and estimate too cautiously the loss of it."

Gentlemen, these suggestive words from so profound a thinker and a man of such matured experience are worth pondering over; and may we not meet with many parallel cases in surgery? I know of no class of cases more important, more interesting, and in which more marked change of treatment has taken place within a number of years, than cases of fracture of the skull, and I think no records can offer a more marked illustration of this latter fact than the records of some of the master minds in surgery who have been connected with the hospital I specially venerate, St. Bartholomew's. Permit me briefly to quote the 
opinion of three men following each other in rapid succession, Pott, Abernethy, and Lawrence.

In Pott's Sur sery', published in I 808 by Sir Jas. Earle, we find that the use of the trephine in almost all fractures of the skull, whether simple or compound, is strcngly insisted upon. He says, speaking generally of these fractures : "The number of cases of this kind which are necessarily brought into a large hospital, so situated as St. Bartholomew's, in the midst of a populous city, where all kinds of hazardous labour are carried on, has enabled me to make many observations upon them and, although $I$ have now and then seen some of them do well without the use of the trephine, yet the much greater number whom I have seen perish with collections of matter within the cranium, who have not been perforated, and for whom there is no other relief in art or nature, has, I must acknowledge, rendered me so very cautious and diffident that, although I will not say that I would always and invariably perform the operation in every case of simple fracture, yet the case must be peculiarly circumstanced, the prospect much fairer than it most frequently is, and my prognosis delivered in the most guarded apprehensive manner when I omit it."

And, again, he expresses his strong opinion, "that enlarging the opening of a fracture by means of a trephine will not produce or occa sion much risk or hazard additional to what must be occasioned by the fracture itself that has already let in air upon the membrane; and, therefore, that that consideration is, at all events, in some degree at an end"; and so he goes on to argue that, as a matter of prevention, operation ought to be had recourse to in nearly all simple or compound fractures of the skull. Moreover, he did not confine his operation to one perforation of the skull, but occasionally trephined in two or three places, so as to embrace the whole of a fracture in the parts so re moved ; and yet I find, in spite of treatment so heroic, not a few successful cases recorded in his work on Surgery.

Abernethy differed in his practice from the course insisted on by Pott. IIe observed that a slight pressure from depressed bone did not interfere with the proper discharge of brain-function ; and, whilst admitting that the pressure so exercised might in some cases set up irritation at a future time, he thought that generally the parts beneath became accustomed to it, and no evil results followed, and he thu cautiously expresses his view of the treatment to be pursued. "From all I have learned from books, as well as from the observations I have made in practice and from reasoning upon the subject, I am disposed to join in opinion with those surgeons who are against trephining in slight depressions of the skull, or small extravasations on the dura mater."

I.awrence held, perhaps, a more decided opinion than Abernethy, he being certainly opposed to interference in cases of fractured skull, except where symptoms or other conditions clearly indicated it. In an able article on Cases of Injury to the Head, by Mr. Evans of the Hull Infirmary, published in the third volume of St. Bartholomeav's Hospitat Reports, Mr. Evans says : "I well remember some years ago the late Sir William Lawrence saying, in the wards of St. Bartholomew's Hospital, where a case had been recently trephined by one of his colleagues, that his experience of forty years in the wards of that hospital was, that such injuries did as well without operation as with it."

Here, then, I have briefly epitomised the opinions of three representative men of one of our great surgical schools, men whose opportunities for observation were immense, and who brought giant minds to bear upon the question; and I could considerably multiply opinion both in favour of and against interference in cases of depressed fracture of the skull, expressed by the leading surgeons of their time. And, though I think I may assert that the balance of opinion is now in favour of interfering extremely rarely in such cases, except where marked symptoms develope themselves, and that certainly a great change in practice has taken place since the teachings of Pott; still, with all the light of past experience to guide us, and with all the recorded results of the practice of the great men of former years for our instruction, the propriety of immediate operation in cases of depressed compound fracture of the skull is still an undecided point in surgery. All authorities agree that, when symptoms of brain-pressure arise as a consequence of such injury, or where inflammatory symptoms develope themselves, not speedily yielding to antiphlogistic treatment, our duty is then to operate by trephining, or using Hey's saw or bone-forceps where practicable, so as to give exit to pus, or remove a source of otherwise fatal irritation; but it seems to me that the important and ye undecided question is, Are we to use these means at first, withou waiting for the development of symptoms, in order to prevent their oc currence? Does the subject of a compound depressed or comminuted fracture of the skull run a greater risk by being trephined at once, though no symptoms exist, or by being left alone?

Two of the most eminent of living authorities strongly advocate im mediate interference; you will almost anticipate me when I mention Mr. Prescott Hewett and Mr. Erichsen.

Mr. Hewett distinctly says that, " in cases of compound depressed fracture of the skull, the rule is to operate, and at once"; and $\mathrm{Mr}$. Erichsen speaks even more emphatically. In his very admirable book on Surgery", he makes the following remarks on the subject. "So far as my own experience is concerned, which is necessarily drawn purely from civil practice, I can say that, with the exception above referred to, I do not recollect ever having seen a case recover in which a compound depressed fracture of the skull occurring in an adult had been left without operation; but I have, on the other hand, seen several in stances of recovery in which the bone had been elevated and fragments removed. The sooner this is done, the better; danger docs not arise from early operation, but from delay; the presence of depressed and spiculated fragments pressing into the dura mater must infallibly and speedily induce encephalitis. I have several times trephined under such circumstances as these with success, and have never had occasion to regret doing so. Indeed, there is no class of cases in which the operation of trephining is attended by such successful results as in those of depressed and comminuted fracture." To what circumstances, then, are we to attribute this diversity of practice amongst men so thoughtful and so well able to form opinions? Possibly the excessive use, I suppose I may say the abuse, of the trephine in former times has been one cause of its almost absolute disuse by British surgeons within late years. I think that, in the case of many powerful and active remedial measures, once highly esteemed and strenuously enforced, as extended observation and scientific research prove to us that their employment is frequently unnecessary and often harmful, we are too apt to rush into the other extreme and altogether discard them, overlooking the value of their cautious and carefully considered employment. Another reason, I think, may be the unfortunate results which statistics give in cases where the trephine has been employed; but here, again, if we carefully investigate the existing conditions in many such cases, we must conclude that the same results would have followed, ir spite of any treatment. The rule of practice with many eminent surgeons is to have recourse to the trephine at once in the treatment of compound depressed fracture, only in such cases as are accompanied by symptoms of brain-compression, and rarely, I fear, with a fortunate result; and, although in loose statistics such cases go to swell the number of deaths recorded after trephining, has the operation itself anything to do with the fatal result?

I think that if we come to examine such cases after death, we should almost invariably find some serious brain-lesion which could hardly have terminated otherwise than fatally whatever treatment we had adopted. Permit me on this point to again quote Mr. Prescott Hewett. "It has never fallen to my lot", says he, "to meet with a single case of cerebral disturbance of a formidable or urgent character, in which such symptoms were wholly dependent upon depressed bone. In every case which I have seen with these symptoms strongly marked, there was also some extensive extravasation of blood, or some serious lesion of the brain-substance itself."

Again, perhaps the most obvious cause of these diverse opinions lies in the fact that, in cases of depressed fracture, we can hardly lay down a hard and fast line of treatment-much must be left to the careful and anxious consideration of the surgeon unhappily meeting with such cases. I think recent experience has abundantly proved that compound depressed fractures of the skull in adults do get well without operative interference; and, in illustration of this fact, I beg for a moment to refer you to three cases published in the BRITISII MEDICAL JOURNAL of July 8th by Mr. Gamgee of Birmingham. Here we find rapid and uninterrupted recovery from compound depressed fracture of the skull in adults, one man being fifty-five years of age, and the other two twenty-five years old. They were all treated by perfect rest, cold to the head, and aperients. I could adduce other instances, but I refer to these as cases recently published, and probably familiar to many readers of the JOURNAI.

On the other hand, it is a well-known fact that such happy terminations are by no means constant, and that the trephine or some similar instrument has sometimes to be used to relieve inflammatory symptoms, which occur as the results of irritation set up by the fractured bone, or to give exit to pus ; even then recovery is by no means to be despaired of, though, of course, operative interference under such circumstances is far less promising than when undertaken without the inflammatory complication. Referring to my notes of cases in the hospital, I find that only once in the last five years have I hatl recourse to the trephine, and I did so in what, I almost think, is a typical case for operation.

H. D., a woman, aged 39, was brought into the infirmary with a history that she was engaged in some street row, and was knocked down by a stone thrown into the crowd. I found a large wound lead- 
ing down to a comminuted punctured fracture, the portions of bone being driven deeply down. There were no head-symptoms. Finding it impossible to pick out the represserl portions with forceps, I removed a semicircular piece of the sound bone with a trephine, and was able then easily to remove six comminuted portions of bone, some of them driven under the uninjured bone, and amounting in the aggregate to a piece as large as a half-crown. The dura mater was scratched, but not punctured. The woman was kept quiet, with cold to her head, and made a rapid recovery without any untoward symptoms. I think I may instance this as a case in which it is extremely doubtful whether so fortunate a result would have been obtained had I refrained from operation. I think, perhaps, there is a tendency in these days to overrate the danger of operative interference in such cases; for, where grave bone injury already exists, and where air has already had access to the dura mater, and probably also foreign bodies, such as grit and dirt, it is open to question whether an operation, such as I have just described, performed with all possible care and delicacy of manipulation, adds very materially to the existing danger.

Certainly, I should be little disposed to lay down a defined line of treatment in cases such as I have been describing. Much must be left to the discretion and anxious thought of the surgeon, and whilst bearing in mind on the one hand that depressed compound fractures of the skull, even in adults, do get well without operation, one ought not to hesitate to interfere where the existing conditions of the fracture are such as to make one feel that there is probably less risk in interference than in simply waiting for results.

But time warns me to leave this most interesting and important surgical question, and to pass on to the consideration of one or two others, with a few brief remarks; and whilst on the subject of bone-injuries, I should like to say a few words upon, and illustrate by an instructive case, and an equally instructive preparation, cases, of fractures of bone in the immediate vicinity of important joints. I think there are few cases in surgery in which the accurate diagnosis is often more difficult, the anxiety involved greater, and the results less satisfactory, than in cases of this nature. Every practical surgeon is familiar with the im. paired utility of wrist and hand which we occasionally see, particularly in old people, as a consequence of the fracture of the carpal end of the radius ; and again, impaired mobility of the elbow-joint is not unfrequently seen, as a result of fracture through some portion of that complicated and important articulation; and I venture to say that such consequences are sometimes unavoidable, in spite of the most carefully conducted treatment; nay, I think I may go even further, and assert that cases do occur in which the surgeon, by skilful and carefully conducted treatment, has obtained the best results he could hope for, and which still are failures in the eye of the patient, ignorant as he is of existing conditions and almost inevitable consequences.

Surely, gentlemen, these considerations should teach us a lesson; they should teach us to look very charitably upon alleged failures in treatment, or upon so-called cases of malpractice. It is one thing to criticise the treatment of a deformed or distorted joint weeks, or perhaps months, after the receipt of injury, when all immediate effects of such injury have disappeared; but it is a very different thing when contusion, inflamimation, swelling, and pain obscure the injury and in terfere with manipulation, so to direct our treatment, as always to ensure a satisfactory result.

The case to which I wish to direct your attention for a few minutes, and which through the kindness of my friend Mr. Wheelhouse I am enabled to illustrate by a very instructive preparation, is one of dislocation of the hip, complicated, as I believe, by fracture of the acetabulum, that is, of the rim of the acetabulum.

A. B., a young man, a commercial traveller, was standing on the platform at a railway station, when he saw the train by which he wanted to travel passing rapidly through the station; he ran up to it, sprang upon the foot-board, and attempted to grasp the door of a carriage, but, being swung round by the momentum of the train, he was unable to keep his hold, and was thrown violently ipon the rails, rolling over and over when he came to the ground. He lay stunned for a few minutes, and when he attempted to get up, found his right leg so injured that he could not rise. He was carried into the waiting-room, and was seen very shortly afterwards by Dr. M., the railway company's local medical officer. This gentleman made a very careful and deliberate examination of the injured limb, and, as manipulation gave great pain, he put the sufferer under the influence of chloroform, so as to give himself every opportunity of arriving at a correct estimate of the nature of the injury. After nearly an hour's examination, he came to the conclusion that there was no dislocation, no fracture, but that the man was suffering from severe contusion. Afterwards, the sufferer was carefully laid in a railway carriage, and conveyed to his home in Manchester. Here he sent for his own surgeon; the same examination again was gone through, and the same result arrived at. As soon as the subsidence of swelling allowed it, a long splint was applied to keep the part perfectly at rest; and subsequently, as much pain about the hip was still complained of, his medical man, for his own satisfaction and that of his patient, called in a third surgeon, a man whose extended experience in cases of accident was undeniable. He found the limb lying flatly on the bed beside its fellow; careful measurements, conducted in the orthodox manner, proved that the injured limb was as long as, and at one time rather longer than, its fellow; and he coincided in the con clusions already formed, and in the propriety of the treatment adopted. And so the limb was kept at rest for some time longer. IIere, then, we have three surgeons, separately and carefully examining this hip, and arriving at the same conclusions. But mark what followed in this singularly interesting case. When lapse of time and subsidence of pain warranted it, the splint was removed, and he was allowed to get upand attempt to move about. Ife did so, and attempted to bear some slight weight upon the injured leg, and after that he noticed, for the first time, that the injured leg was rather shorter than the sound one. This amount of shortening speedily increased to the extent of a couple of inches, with inversion of the foot; and, to cut a long story short, he consulted a fourth surgeon, who told him that his hip was dislocated ; and eventually an action for damages ensued. In consequence of this, Mr. Wheelhouse of Leeds and I were asked to examine the case, and give evidence upon it. When we saw it, several months after the accident, the evidences of dislocation were clear enough; there were the characteristic shortening, the inverted foot, and the round head of the bone clearly resting upon the dorsum of the ilium. One of two things, then, must have happened in this case. Either (as was alleged) dislocation of the hip had occurred at the time of the accident, and had been overlooked, or else dislocation had taken place subsequently, as a result of some obscure injury to the joint. Against the first hypothesis were the testimony of three surgeons, who had all examined it carefully for dislocation or fracture, the fact of the absence of deformity, and the absence of shortening of the limb; whilst in favour of the latter hypothesis, in addition to what I have just stated, was the fact that no shortening took place till the man put weight upon the leg, and then it was immediately noticed. The only way in which one could reconcile the fact of undoubted present dislocation, with a history so opposed to its existence for some time after the accident, was on the hypothesis that, at the time of the accident, which was a very violent one, there was fracture of the rim of the acetabulum; that, so long as no weight was put upon the leg, the head of the femur remained in situ; but that as soon as weight was borne upon the leg, the head of the bone escaped from the damaged acetabulum, and was soon drawn up upon the dorsum of the ilium. This theory was very ably argued by $\mathrm{Mr}$. Wheclhouse, and surely it was a reasonable one-more reasonable than that a dislocation presenting such marked features as dislocation of the femur on the dorsum ilii, should have been overlooked, though carefully searched for, by so many surgeons of ability and experience; and, though the probability of such an occurrence was denied, I am in a position, through the kindness of $\mathrm{Mr}$. Wheelhouse, to show you a preparation taken from a case of accident admitted into the Leeds Infirmary, since the occurrence I have just related, which admirably illustrates the argument then urged. The case was admitted into the infirmary for injury to the hip and severe internal injuries. Dislocation was diagnosed, and reduction readily effected. The patient lay in bed some days, and then died from internal injuries. During the removal of the patient from the bed, the hip, which had been in perfectly good position so long as the man was at rest, again became dislocated, and a post mortem examination revealed the condition I now show you, viz., "fracture of the rim of the acetabulum".

Erichsen, speaking of the treatment of such cases, says : "But with every care, a return of displacement will readily take place, and an unsatisfactory result can scarcely be avoided-shortening of the limb, and consequent lameness, being a!most inevitable". Cases such as this one I have just related are of immense practical interest both to the surgeon and his patient; certainly the patient has a right to expect that everything shall be done for him that careful judgment and judicious management can effect ; but how often does the surgeon get undeserved blame, when he has the misfortune to treat an injury so complicated that, in spite of all care and skill, he cannot avert an unsatisfactory result. I can imagine and excuse a man being angry, when he finds himself permanently crippled by an accident, which at first, to all appearance, may not have seemed of a very formidable nature ; but surely we, fellowworkers, all so fallible, ought to criticise the work of our brothers in a spirit of the widest charity.

The mention of Mr. Wheelhouse's name in connection with this case, in which I was associated with him, reminds me how this address was criginally placed in his hands, and how generously and gracefully he 
relinquished it when the place of meeting was changed, and gives me the opportunity of paying a passing tribute to his surgical enterprise, by a few remarks on what, as far as I know, is an important and an ingenious novelty in surgery. Some months ago, I had an opportunity of examining in the Leeds Infirmary a case then under treatment, in which Mr. Wheelhouse had cut down upon, resected, and united by ligature, the divided ends of a sciatic nerve, which had been accidentally cut across some months previously. The history of the case was briefly as follows.

The patient, a man aged 22, nine months before admission, was climbing over a fence, when the railings gave way, and he fell backwards upon a scythe which he was carrying. The wound, which mus have been an extensive one, as the cicatrix measured nine inches, was situated just below the left buttock. At the time of admission, he was able to walk with difficulty, there being considerable dragging of the left leg, and, as he lifted it, the toes fell to the ground. He was unable to use the muscles of the back of the leg, and there was loss of sensation on the outer side of the leg and foot, the inner side retaining sensation. These conditions, taken in connection with the situation of the cicatrix, led to the inference that the great sciatic nerve had been divided, resulting in paralysis of parts supplied by that nerve below the seat of division. The operation consisted in making an incision six inches in length in the course of the sciatic nerve, when the divided extremities were found an inch and a half apart, the upper segment being bulbous, the lower one flattened, and somewhat incorporated with the cicatrix. The two extremities were then cut off, the divided ends brought together, and retained by sutures of carbolisec catgut. This was facilitated by flexing the leg upon the thigh, in which position it was retained for some time. The man made a rapid recovery. When I saw him, two or three weeks after operation, cicatrisation was almost complete, though the leg was still retained in its flexed position; but there was ample evidence afforded of returning sensation on the outer side of the leg and foot. In this case, the restoration of sensation and motion appears to have been very gradual ; but $\mathrm{Mr}$. Wheelhouse informs me that, since his discharge from the hospital, the patient has gone on steadily improving, and gaining power in his former paralysed limb.

I have also the notes of a case of division of the median nerve by a wound from glass. It was treated in the same way, ten weeks after the accident happened ; but the result does not appear to have been so satisfactory, as, though some amount of return of sensation and motion followed the operation, as the wound healed and cicatrisation progressed, the sensation gradually diminished and numbness increased.

Two other cases I have records of, in which the divided ends of the nerves were brought together by suture immediately after the accident. In one case the median nerve, and in the other the ulnar nerve, were entirely divided. Both cases were boys of fourteen years of age. In one month from the occurrence of the accident, both boys were discharged with their wounds healed, and sensation was perfect in each instance.

Now, I think I may instance these as four very suggestive cases. Perhaps they teach us no new facts in pathology ; but, practically speaking, I think they are of importance. It will be observed that in the two cases in which some weeks elapsed between the receipt of injury and operation, the results were in one case very gradual and slow in their development, and in the other case satisfactory ; but in the two cases in which operation immediately followed the accident, sensation, at all events, was rapidly re-established. Now, experience has amply proved that regeneration of nerve-tissue after nerve division readily takes place more or less perfectly under favourable conditions. Dr. Hassall says : "The regeneration of the primitive nerve-tube admits of proof both by experiment and direct observation. The experimental proof consists in the simple division of nerves, or even in the removal of portions of them. The parts to which the nerve is distributed of course at first lose their sensory and motor endowments; these, however, after a variable time, are more or less perfectly recovered, thus completing the experimental proof. The recovery of the power of a nerve after the excision of a portion of it, argues strangly the fact of the regeneration of the nerve-tubes; and this result, by a careful microscopical examination, can be positively demonstrated. The number of tubes in the renewed part of the nerve is stated, however, to be less than in the original portions ; and this, in part, explains the reason of the restoration of the functions of a divided nerve being usually but imperfect." Every surgeon, too, is familiar with the fact, that parts which have been completely severed, such as tips of fingers, will, if re-united, regain sensation, though the nerves have been completely divided. Thus, under favourable conditions of position, we may look for such an amount of return of sensation and power of motion in parts supplied by divided nerves, as shall not ma. terially interfere with future usefulness : but the practical lesson to be learnt from such cases as these is, that we may with safety so manipulate nerves as to insure such conditions of position. Perhaps the very painful, and sometimes even disastrous, result which has followed the ligature of an important nerve, has deterred surgeons from interfering with them when divided. Sir A. Cooper records two cases of death from this cause-one from the ligature of the sciatic nerve to arrest hæmorrhage from an artery in its substance, and another in which the popliteal nerve was accidentally included in a ligature put round the artery. In both cases violent pains and death resulted.

In the cases I have recorded, I find complaint of much pain after operation in only one case-the first one operated on, in which the sciatic nerve was the one implicated. In this case there seems to have been great pain on the day of operation and the day following, but in the other three no mention is made of any disturbance caused by the operation. Probably the use of catgut-suture, which, we know, soon dissolves, and the fact that the sheath of the nerves was carefully selected, as the portion to be principally included in the sutures, may have had much to do with such fortunate results.

As a beginning, then, I think these four cases are both interesting and encouraging. If in the case of a limb left paralysed by division of an important nerve, we can afterwards cut down upon, resect, and reunite such nerve, so as to restore power and sensibility to the parts supplied by it, at no great risk, much has been gained ; and in cases of extensive wound or laceration, involving important nerve-trunks, these records raise the question whether it is not better not to be simply content with ligaturing bleeding vessels, and leave the nerve-trunk to the chance of assuming its original position, by carefully and accurately closing the wound, but to insure the co-aptation of is divided ends by the careful introduction of catgut-suture.

I wish to say a few words upon Esmarch's elastic bandage and constricting band ; for the case of cure of aneurism in the popliteal space, recently published by Dr. Reid of the Naval Hospital at Plymouth, as effected by the application of Esmarch's method for restraining hæmorrhage, is well deserving of consideration.

Operating surgeons constantly come into contact with cases in which, either to themselves or their patients, the application of Esmarch's apparatus is a great advantage. In a town like Sheffield, where very heavy manufacture is going on, and where much machinery and steam power are employed, severe accidents, entailing great hamorrhage, are very common; and repeatedly have we found the advantage of Esmarch's method in the amputation of mutilated limbs, where every drop of blood is of consequence. And, again, how much the work of the surgeon is facilitated in such operations as the removal of sequestra surrounded by new bone, and in the midst of soft structures, often unusually vascular from long-continued local activity. Here his view of parts is not obscured by the constant welling up of blood, and he is able to remove dead bone with the least possible damage to the new formation surrounding it, and acting as a substitute for it. In such operations, too, as those upon the foot, necessitating the disarticulation of small bones, with anatomical relations often obscured by disease and swelling, its advantages are obvious.

Esmarch's method thus secures a twofold desideratum, in cases where its application is practicable, for it procures for the surgeon as clear a view of the parts he is operating upon as if he were operating on a dead body, and it secures for the patient the great boon of undergoing operation with the least possible loss of blood. I know it has been urged, in objection to its employment, that there is the risk of squeezing up into parts above inflammatory products, blood-clots, or partially disorganised blood, but I think with care in the application such accidents can rarely happen. Often as I have applied it, I never remember to have come across such results. The only unfortunate effects I have seen, I think, have been minor ones, such as some bruising and subsequent swelling of the stump, when probably the elastic ligature has been applied more energetically than was necessary. The method can hardly be called a new one, though I think to the ingenuity of Esmarch we are indebted for devising the means of making it so widely and generally practicable. But over and above these well known and generally acknowledged advantages, I must for a few minutes draw your attention to its employment for another purpose-the cure of aneurism. The subject of aneurism was so fully and exhaustively treated by $\mathrm{Mr}$. Pemberton of Birmingham before this Association, four years ago, that little can be added to what he then advanced; but in the case recorded by Dr. Reid, when ordinary appliances failed, a rapid cure was effected by the application of Esmarch's bandage and ligature. The subject was a sailor, aged 37 , with popliteal aneurism. Compression was first tried by genuflexion, which caused so much pain and oclema of the leg that it had soon to be discontinued. Afterwards, Carte's compressor was applied at the brim of the pelvis, and again in Scarpa's 
space ; but after four hours' continuous compression, severe pain again put a stop to treatment; and though pulsation in the tumour had ceased, it shortly returned, the opinion being that, although circulation through the femoral was controlled, a free supply of blood entered the sac through the collateral branches. It was then determined to try the effect of Esmarch's apparatus, not so as to empty the sac of blood, but keeping it filled, so to cut off all circulation through the limb as to allow of the coagulation of the contents of the sac. The limb was enveloped in the bandage from the toes upwards, but the bandage was passed very lightly over the knee, so as to exercise little pressure on the sac, and the thigh was then enveloped to the micldle third. The elastic ligature was passed round the thigh, and kept on for fifty minutes, when pain above the seat of the constriction necessitated its removal. It was then found that all pulsation had ceased; the aneurismal tumour was hard, and, as a means of precaution, a tourniquet was applied, at intervals, over the femoral for a few hours longer, to moderate the current of blood through the artery. Pulsation never returned, however, and the man when seen some months afterwards was perfectly well. The striking feature in this case is the rapid cure. One can readily understand stagnant blood, in a vessel in a limb almost deprived temporarily of vitality, speedily coagulating; but it will be observed that this is not precisely the method of cure which we have been in the habit of considering the most desirable in aneurism. The efforts of surgeons, from John Hunter's time, has been so to retard the flow of blood as to encourage the deposition of lamina of fibrine till a sac becomes filled. In his address in surgery at Birmingham, Mr. Pemberton says: "What we want is a stream of blood flowing into the aneurism, that it should be more or less retarded there, and that there should be present something of the nature of a foreign body-for example, the fibrous laminz-on which blood would coagulate and deposit its fibrine, for I strongly hold that what we want in these cases is a deposition of fibrine rather than a coagulation of blood. Surely, the slow deposition, layer after layer, of solid fibrine in the sac, until filling in is complete, is a surer guarantee against future mishaps than if it were closed by a mass of suddenly coagulated blood." Now, whilst fully admitting the soundness of the views here expressed, I still consider this case well worthy of the attentive consideration of the surgeon. Certainly, I would prefer the gradnal consolidation of the aneurismal sac by the deposition of fibrinous lamina; but I am sure I have seen cases in which, either from the shape of the aneurismal swelling, or from the briskness of the collateral circulation, attempts to obtain consolidation by retarding the flow of blood have been useless; and, again, the pain induced by long-continued compression, or the nervous irritability of the sufferer causing him to be intensely sensitive to pain, may thwart our efforts to produce this gradual consolidation. Without presuming to draw conclusions from a single case, I still venture to bring this interesting one before the members of our Association, affording as it does another and a novel illustration of the benefits conferred upon surgery by Esmarch. And if further experience prove that, in cases where we fail to obtain the gradual consolidation at which we have hitherto aimed, we can obtain rapid and lasting coagulation by actually stopping circulation in a limb, we shall have made another very important addition to the methods alrearly in use for the cure of aneurism.

Gentlemen, I feel I have already trespassed long enough on your patience. I wish my crucle and imperfect remarks had been more worthy of your consideration. I have been able to tell you little that is new, and nothing that is original. It is given only to the gifted few to originate ideas and introduce innovations. But still I may hope to have completed a far from useless task if $I$ have succeeded in interesting this large representative gathering, in even one or two important surgical questions ; for it is only by the accumulation of facts, and by the interchange of experiences, that we can hope to throw light upon those delicate and difficult problems in which the profession we love so well abounds.

Wholly occupied, as many of us are, in the pressing practical work of our profession, too little time can frequently be devoted to the scientific and more attractive side of it; and yet the humblest worker in our great field of labour, diligently and conscientiously doing his daily work, may reap a rich reward ; for, even before wealth and honour, welcome as they are, is the gratitude of our fellow-men for benefits conferred upon them, and the peace that comes from a life spent in trying to alleviate the sufferings of our fellow-crentures.

A REPRIEVE arrived in Leicester, on Saturday night, for the culprit Cornelius Asher, aged 77, herbalist, sentenced to death by Mr. Justice Field, at the recent Leicester Borough Assizes, for the murder of Ann Gee, on May 2nd, and whose execution had been fixed for Monday mrorning.

\section{ADDRESS IN PUBLIC MEDICINE,}

\author{
ALFRED CARPENTER, M.D., C.S.S.CAMB.
}

A.Parliamentary leader has spread far and wide the proposition : Salus populi suprema lex. We are bound to believe that, when he uttered that sentiment, he honestly gave adhesion to the principle involved in it. Nay, the harassing legislation which a belief in its correctness helped to promote, has assisted to bring about the ebb-tide in the promotion of sanitary work which we are now witnessing. It may be thought that a proposition which has become a proverb, cannot be accepted as an axiom; the epitome of abridged wisdom which is wrapped up in its meaning being lost sight of. Such is the proposition to which the then Prime Minister gave utterance nearly three years ago, and which should be the watch-word of the Health Department of this Association. The questions which are involved in the proposition are manifold, and their prosecution by the members of the medical profession has produced a greater number of enemies than it has brought friends.

Ebb-tide in sanitary work, however, is not to be wondered at. Terence wrote in ancient times:

"Obsequium amicos, veritas odium parit";

and as in times of old so it is now, obsequiousness has no place in the performance of duty, and as a natural consequence its prosecution promotes opposition. It is my present purpose to show why opposition is attended with so much apparent success, to point out simple lines of progress, and propound a theory as a basis for continued exertion.

It is scarcely more than forty years since the first national platform was established upon which satisfactory observations could be made, and successful operations carried on in the cause of preventive medicine. The statistics which have been prepared by William Farr, have been true pioneers of sanitary work. I would by no means decry the observations made by the older sanitarians. Howard and Pringle, Harvey and Jenner, with many other older workmen, are worthy of the highest regard by those who value the work in which we are engaged, and who think prevention of greater national importance than cure. If it had not been for the work of these eminent men, followed as it was by that of the enlightened politicians who framed and passed the Factory Act of 1833 , and the Registration Act of 1834 , William Farr's records would not now be matters of history, and we might still be groping in the dark as to the natural laws which regulate the health of the people, and be theorising as to the causation of disease, instead of calling upon Parliament to legislate for its prevention. The facts which have been brought to light by Farr's tables, the enormous mortality which has been shown to exist in defined districts, among defined classes of persons, and at particular epochs in their lives, together with the philosophical and suggestive papers which have been prepared by, or at the suggestion of, one who deserves as much of his country as any living man-I mean John Simon-have led to a flood of legislative measures, sometimes contradictory, passed in paroxysms; too often spasmodic in their character and unsatisfactory in their working ; culminating at last in the enactment of a measure, which made the appointment of medical officers of health compulsory upon all local sanitary authorities. This measure has laid a foundation which enables us to apply particular observations to defined localities all over the country. The compulsory appintment of those medical officers was preceded by a permissive stage - permissive, first, in the application of sanitary worl: to a particular district-permissive, in the way in which that work should be applied, but at the same time accompanied by the stern resolves of the courts of law that, in applying those works, and bringing them into practice, the rights of individuals should be respected. The aatagonism between the suprema lex and the liberty of the subject; the opposition between salus populi and the rights of property, contirued to throw serious impediments in the way of sanitary progress, because the truths of sanitary science were few, whilst the ipse dixits of its professors, both medical and engineering, were numerous and contradictory. Especially has this been the case with the comparatively new profession of sanitary engineers, a profession which has sprung up to execute the works which sanitary science has called for; the members of which profession, in a large number of instances, were ignorant of natural science. Is it to be wondered at that Parliarnent in its wisdom passed permissive 